\title{
Urban Education
}

http://uex.sagepub.com/

\section{Ethnic School Segregation and Self-Esteem : The Role of Teacher- Pupil Relationships}

Orhan Agirdag, Mieke Van Houtte and Piet Van Avermaet

Urban Education 2012 47: 1135 originally published online 16 July 2012

DOI: $10.1177 / 0042085912452154$

The online version of this article can be found at:

http://uex.sagepub.com/content/47/6/1135

\author{
Published by: \\ (3)SAGE \\ http://www.sagepublications.com
}

Additional services and information for Urban Education can be found at:

Email Alerts: http://uex.sagepub.com/cgi/alerts

Subscriptions: http://uex.sagepub.com/subscriptions

Reprints: http://www.sagepub.com/journalsReprints.nav

Permissions: http://www.sagepub.com/journalsPermissions.nav

Citations: http://uex.sagepub.com/content/47/6/1135.refs.html

>> Version of Record - Oct 23, 2012

OnlineFirst Version of Record - Jul 16, 2012

What is This? 


\section{Ethnic School}

\section{Segregation and}

Self-Esteem: The

Role of Teacher-

Pupil Relationships
Urban Education

47(6) $1135-1159$

(C) The Author(s) 2012

Reprints and permission: sagepub.com/journalsPermissions.nav

DOI: 10.1 I77/0042085912452154 http://uex.sagepub.com

(SAGE

\title{
Orhan Agirdag', Mieke Van Houtte', and Piet Van Avermaet'
}

\begin{abstract}
The authors examine whether school segregation is related to pupils' global self-esteem and whether this association is mediated by teacher-pupil relationships. Multilevel analyses based on a survey of 2,845 pupils (aged 10 to 12) in 68 primary schools in Belgian urban areas reveal that, for nativeBelgian pupils, a higher proportion of immigrants at school is associated with increasing self-esteem. Initially no such association was found for immigrant pupils, as the effect of schools' ethnic composition on their self-esteem was suppressed by teacher-pupil relationships. For both groups, experiences of supportive relationships with teachers were largely associated with selfesteem.
\end{abstract}

\section{Keywords}

student self-esteem, urban education, ethnic school composition, school segregation, teacher-pupil relationship, teacher support, global self-esteem, racial school composition, school diversity

'Ghent University, Ghent, Belgium

Corresponding Author:

Orhan Agirdag, Ghent University, Korte Meer 5, Ghent, 9000, Belgium

Email: orhan.agirdag@ugent.be 


\section{Introduction}

The assumption that ethnic minority children tended to have lower selfesteem in ethnically and racially segregated schools was a central argument of the early advocates of desegregation policies, one of the key motives of the historical decision by the U.S. Supreme Court in Brown v. Board of Education that ended de jure school segregation (Bankston \& Zhou, 2002; Zirkel, 2005). Paradoxically, from the late 1960s onwards, sociological and educational research has repeatedly demonstrated that ethnic minority children (mostly African American) in fact exhibit equal or even higher selfesteem in de facto segregated schools than in desegregated schools, that is, schools with a higher share of ethnic majority (mostly White) pupils (Drury, 1980; Gray-Little \& Hafdahl, 2000; Powell, 1985; Rosenberg \& Simmons, 1972; Stephan, 1978). This evidence of the potential harmful consequences of school desegregation on self-esteem has been used as a major argument against school desegregation policies (see Bankston \& Zhou, 2002). After all, self-esteem is an essential part of students' quality of school life and is related to improved socioemotional adjustment and increased community involvement, academic performance, and aspirations (Hoffman, Knight, \& Wallach, 2007; Pullmann \& Allik, 2008; Rosenberg, Schooler, Schoenbach, \& Rosenberg, 1995; Yogev \& Ilan, 1987).

To explain the relationship between school composition and pupils' selfconcepts, previous studies considered mutual social comparisons among pupils (e.g., Drury, 1980; Gray-Little \& Carels, 1997; Marsh, 1987). However, theorists emphasize that social comparison is just one of the various sources of self-esteem. For instance, social and emotional relationships might also be related to ones self-esteem (Brutsaert, 1990). In this study, we argue that within the school context the social relationships between teachers and pupils (hereafter teacher-pupil relationships) might play a decisive role as these relationships might have an impact on pupils' global self-esteem. Previous studies have demonstrated that teacher-pupil relationships are dependent on schools' compositional characteristics (Crosnoe, Johnson, \& Elder, 2004; Van Maele \& Van Houtte, 2011), and other studies have shown that teacher-pupil relationships, in turn, have an impact on pupils' selfesteem (Reddy, Rhodes, \& Mulhall, 2003; Roeser \& Eccles, 1998). Yet we do not know of any study that has considered the mediating role of teacherpupil relationships for the association between ethnic school composition and pupils' self-esteem. Moreover, most studies on the effects of ethnic school composition on self-esteem are conducted in the United States, and they 
mostly consider the impact on ethnic minority pupils' self-esteem (for an exceptional study in the Netherlands, see Verkuyten \& Thijs, 2004).

Hence, in Flanders, the Dutch-speaking part of Belgium where the present study was conducted - research on the effects of ethnic school composition on pupils' self-esteem is nonexistent. The ethnic minorities in Flemish schools are mainly the children and grandchildren of Turkish and Moroccan families. Their families have mainly immigrated after the Second World War to address the labor shortage. In many ways, the contemporary socioeconomic situation of these immigrants groups resembles that of Blacks in the United States, whom Ogbu (1991) referred to as involuntary or caste-like minorities. Especially the second- and third-generation citizens - born in Belgium-did not choose to be in Belgium and seem to have had their minority status inflicted on them against their will (see Van Houtte \& Stevens, 2009). Therefore, with this article we aim to fill these research lacunae. More specifically, using multilevel techniques, we will examine the impact of ethnic school composition on ethnic majority (native Belgian) and ethnic minority (immigrant) pupils, and the mediating role of teacher-pupil relationships.

\section{Ethnic Composition and Global Self-Esteem}

Global self-esteem is defined as an individual's overall positive evaluation of the self, and it is highly dependent on the contextual characteristics of one's social environment (Rosenberg \& Simmons, 1972; Rosenberg et al., 1995). When it comes to children, the school context can hardly be neglected, since children spend almost half their waking hours at school. In this study, we focus on the impact of schools' ethnic composition on global self-esteem. Regarding this composition, we make a distinction between two different conceptualizations, that is, ethnic minority concentration and ethnic heterogeneity (see also Agirdag, Van Houtte, \& Van Avermaet, 2011; Chan \& Birman, 2009). Ethnic minority concentration refers to the proportion of ethnic minorities in a given school. Ethnic heterogeneity or diversity, on the other hand, refers to the degree of ethnic differences in a given context. The latter is a "color-blind" conceptualization of ethnic composition. For instance, School A with $90 \%$ Black students and 10\% White students is equally ethnically heterogeneous to School B with 10\% Black and 90\% White students, although School A has a higher ethnic minority concentration than School B. Theoretically seen and regarding previous studies (cf. infra), these two conceptualizations of ethnic composition will generate different results regarding teacher-pupil relationships and pupils' self-esteem. 
Most previous studies that have investigated the impact of ethnic minority concentration found higher self-esteem among ethnic minority children in schools with a higher ethnic minority concentration than those in schools with a lower ethnic minority concentration (see meta-reviews by Gray-Little \& Hafdahl, 2000; St. John, 1975; Stephan, 1978). Most of these studies were conducted among African Americans so that studies of the effects of ethnic school composition on the self-esteem of ethnic majority pupils are less common. One notable exception is a study in the Netherlands by Verkuyten and Thijs. In contrast to the research from the United States, this study found that ethnic composition was only related to the global self-esteem of ethnic majority (native Dutch) pupils: In schools with a higher proportion of ethnic minority pupils higher self-esteem was found for native Dutch pupils, whereas ethnic composition was not related to the self-esteem of ethnic minority (immigrant) pupils (Turkish, Moroccan, and Surinamese). The schools' ethnic heterogeneity, on the other hand, was not found to be related to pupils' self-esteem (Verkuyten \& Thijs, 2004).

In order to explain the effects of school composition, past research has focused mainly on mutual comparison among pupils. Drawing upon social comparison theory (Festinger, 1954) and reference group theory (Merton, 1968), they posit that students' self-concept is dependent on the comparisons they make with their schoolmates. For instance, they argue that African American students in segregated environments are partly insulated from crossracial comparisons that potentially undermine their self-esteem in desegregated schools, that is, schools with a lower concentration of African Americans (see Drury, 1980; Gray-Little \& Carels, 1997). Similarly, the frog pond theory of Davis (1966) and big-fish-little-pond effect of Marsh $(1987,1990)$ insist that the impact of school composition on students' self-concepts can (partly) be explained by mutual comparison among pupils. In other words, in order to explain the impact of compositional school features, past research has mainly focused on pupils' peer group as being salient for their self-esteem (e.g., Van Houtte, Demanet, \& Stevens, 2012). However, schoolmates are not the only social actors in the school context who might have an influence on pupils' self-esteem. Next, we explore the role of teacher-pupil relationships.

\section{Teacher-Pupil Relationships and Self-Esteem}

From the 1980s onwards, educational researchers investigated the impact of teacher-pupil relationships on pupils' school adjustment. Studies on this subject relied mainly on the theoretical frameworks of the attachment theory (Bowlby, 1982) and theory of social capital (Coleman, 1988). Originally focusing on parent-child relationships, attachment theory insists that a 
supportive, warm, and secure relationships with adult caregivers have a positive impact on the socioemotional development of a child (Bowlby, 1982). Drawing on attachment theory, empirical studies reveal that supportive and close relationships between teachers and pupils contribute positively to pupils' academic performance, well-being, and school involvement, in contrast to teacher-pupil relationships of conflict and dependency (Birch \& Ladd, 1997; Buyse, Verschueren, Verachtert, \& Van Damme, 2009; Hamre \& Pianta, 2001; Murray \& Greenberg, 2000; Wentzel, 1998). Whereas this attachment theory is primarily used by educational psychologists, sociologically oriented researchers rely on Coleman's social capital theory as a basis for understanding teacher-pupil relationship patterns and their impact on pupils' outcomes (see Crosnoe et al., 2004; Muller, 2001). According to Coleman (1988), social relationships can create social capital where they function as resources for individuals, and it is less likely that these resources would be present if these relationships did not exist. Similar to relationships between parents and children, relationships between teachers and pupils are a crucial source of intergenerational bonding for the children. Moreover, the potential social capital present in a teacher-pupil relationship is quite irreplaceable given the central decisive role of the teacher in the educational system (see Muller, 2001). Applying the framework of social capital theory, empirical research has consistently found support for the argument that positive teacher-student bonds have a positive impact on pupils' outcomes, such as academic motivation and performance (Goodenow, 1993; Muller, 2001). More important, previous studies also demonstrated that a favorable teacher-pupil relationship is positively related to pupils' self-esteem (Harter, 1996; Reddy et al., 2003; Roeser \& Eccles, 1998; Ryan, Stiller, \& Lynch, 1994). These authors have investigated different aspects of teacher-pupil relationships. For example, Reddy and colleagues find that teacher support, measured by students' perceptions of received support, was positively related to students' self-esteem. Roeser and Eccles show that a positive teacher regard, measured by students' perception of what their teachers thinks about them, predicts a significant increase in self-esteem. Harter reports that teacher support, in terms of perceived teacher approval by pupils, correlates highly with pupils' self-esteem.

\section{Ethnic Composition and Teacher-Pupil Relationships}

The teacher-pupil relationships described above might, in turn, be dependent on the ethnic composition of the student body and thus mediate the impact of ethnic school composition on pupils' self-esteem. With respect to this 
composition, we have already mentioned the important distinction between ethnic minority concentration of schools and the ethnic heterogeneity of schools. Regarding the association between ethnic minority concentration and teacher-pupil relationships, the "functional substitution" perspective can be considered (see Mirowsky \& Ross, 1989). According to the "functional substitution" concept, any given source of social support is more important for individuals' functioning in contexts with fewer overall social resources (see Cooper \& Crosnoe, 2007; Mirowsky \& Ross, 1989).

With regard to schools' ethnic minority concentration, previous studies have demonstrated that ethnic minority pupils develop less supportive relationships with their peers in schools with a lower share of ethnic minorities and that the reverse holds true for ethnic majority pupils. For instance, different studies have revealed that pupils from a particular ethnic group are more victimized by their peers in schools where the size of their ethnic group is smaller (Agirdag, Demanet, Van Houtte, \& Van Avermaet, 2011; Juvonen, Nishina, \& Graham, 2001; Verkuyten \& Thijs, 2002). As such, ethnic minority pupils in schools with a lower ethnic minority concentration might show improved teacher-pupil relationships as a compensation for the less supportive relationships with their peers in such schools, with the reverse being likely for ethnic majority pupils.

Regarding the association between ethnic heterogeneity and teacher-pupil relationships, we consider "constrict theory," as stated by Putnam. According to constrict theory, the degree of ethnic heterogeneity or diversity in a given context reduces the amount of social relationships and bonding with others: 'people living in ethnically diverse settings appear to 'hunker down,' that is, to pull in like a turtle" (Putnam, 2007, p. 149). It should be noted that Putnam states that this tendency applies only to the short term; in the long term, the wider benefits of ethnic diversity are evident. However, in the short term, ethnically diverse settings are likely to be associated with a decrease in social relationships for individuals in such contexts. Based on the premises of the constrict theory, ethnic school heterogeneity can be expected to negatively impact teacher-pupil relationships since pupils in such schools are likely to develop fewer social relationships in general.

The vast majority of quantitative research into the effects of ethnic school composition deals only with its impact on pupils' academic achievement outcomes (for a review see Thrupp, Lauder, \& Robinson, 2002), and only a small number of large-scale quantitative studies have focused on the effect of ethnic school composition on teacher-pupil relationships (Crosnoe et al., 2004; Van Maele \& Van Houtte, 2011). These few studies found that the ethnic context of the school has a significant effect on these relationships. Crosnoe and colleagues showed that students reported more bonding with 
their teachers in schools with less ethnic heterogeneity, that is, in schools with a greater match between individual students and the student body. Van Maele and Van Houtte have demonstrated that in schools with a higher ethnic minority concentration teachers tend to report less trust in pupils.

\section{Current Study}

In sum, there are theoretical arguments and empirical evidence that ethnic school composition, either measured by the ethnic concentration or ethnic heterogeneity, is related to teacher-pupil relationships. In addition, these teacherpupil relationships, in turn, can be expected to have an impact on pupils' self-esteem. On the basis of this premise, we can expect that teacher-pupil relationships will mediate the effect of ethnic school composition on pupils' self-esteem. To be more specific, we will investigate the mediating role of teacher support, which is "the extent to which students believe teachers value and establish personal relationships with them" (Ryan \& Patrick, 2001, p. 440).

Most of the previous studies examine the teacher-pupil relationship only on the individual level. However, as noted by Buyse and colleagues (2009), the average level of teacher-pupil relationship (they call this the "relational climate") might have an impact as well, over and above individual-level teacher-pupil relationships. Pupils do not go to school in a social vacuum but are affected by their peers' beliefs as well. Therefore, much like pupils' individual beliefs about teacher support, their collectively shared beliefs (i.e., their culture) about teacher support in their school, hence pupils' teacher support culture in schools, can be expected to have a positive impact on pupils' self-esteem; we refer to Van Houtte (2005) for an elaborated discussion of the concept of school culture as distinct from school climate. In other words, not only individual pupils' beliefs about their relationships with their teachers matter, the beliefs of their peer group might also play a role. Therefore, in this study we will also focus on pupils' collectively shared beliefs about their relationships with their teacher at the school level. To be more specific, at the school level, we investigate the impact of teacher support culture, that is, the average level of perceived teacher support that is shared by a peer group within a school.

\section{Method}

\section{Sample}

We used data gathered during the academic year 2008-2009, from 2,845 pupils (mean age 11.61) in a sample of 68 primary schools in Flanders as part 
of the Segregation in Primary Education in Flanders (SIPEF) project. Multistage sampling was conducted. In the first instance, in order to encompass the entire range of ethnic composition, we selected three cities in Flanders that had relatively ethnically diverse populations. Second, using data gathered from the Flemish Educational Department, we chose 116 primary schools within these selected cities and asked them to participate. Fiftyfour percent of the schools agreed to do so. The schools in the data set encompassed the entire range of ethnic composition, from those with almost no non-Western immigrant pupils to those composed entirely of nonWestern immigrant pupils. In all the schools that agreed to participate, our research team administered a questionnaire with all the fifth-grade pupils present at the school. If there were fewer than 30 fifth-grade pupils present then we surveyed all the sixth-grade pupils as well.

\section{Research Design}

Because the data set was made up of a clustered sample of pupils nested within schools and involved variables at different levels (pupil-level and school-level), the use of hierarchical linear modeling (HLM; multilevel modeling) is most appropriate. More specifically, we used two-level, randomintercept, random-slope multilevel modeling (SAS Proc Mixed, Singer, 1998). As Proc Mixed provides only unstandardized gamma coefficients, we standardize these coefficients to evaluate the strength of the associations. Standardization is achieved by multiplying the unstandardized coefficients by the standard deviation of the explanatory variable and dividing it by the standard deviation of the dependent variable.

To get a clear view on the distinct determinants for immigrant and native Belgian students, we carried out each analysis separately for both groups. When relevant or needed, for instance, to assess whether or not we are dealing with an interaction of ethnic composition and immigrant background, coefficients for both groups are compared by means of a $t$ test (see Jaccard, Turrisi, \& Wan, 1990). Although the group comparisons could also be examined by including interaction terms within the same model, this approach would result in a considerable loss of power of the analysis: Only in order to asses the group differences for the two ethnic composition variables, more than six cross-level interaction terms needed to be included. Therefore, doing analysis separately for both groups and statistically comparing regression coefficients is a far more straightforward approach.

As is common in multilevel analyses, we began by estimating the unconditional models to determine the amount of variance in global self-esteem 
that occurs among schools for both native Belgian and immigrant pupils. We added the variables stepwise into the model to ensure that we had a clear understanding of mediational effects. We began by examining the effect of ethnic school composition variables, that is, ethnic school composition and ethnic heterogeneity.

To exclude selection effects, we included control variables in the second model. At the school level we also controlled for school sector and school size. Initially, we aimed to control for socioeconomic status (SES) composition as well. However, there was a high correlation between schools' SES and ethnic composition (Pearson $r=-.89$ ). Including both variables in the same model would thus cause multicollinearity problems. As the focus of this study is on the impact of ethnic school composition, we decided to exclude SES composition. Nevertheless, it should be noted that we controlled for SES differences at the individual level, as well as for gender, grade, and academic achievement. In the third model, we entered teacher support (individual level) and teacher support culture (school level) to evaluate whether mediational relationships exist.

In variables measured by means of a scale, responses were imputed for missing values by way of item correlation substitution: A missing value for one item is replaced by the value of the item correlating most highly with that item (Huisman, 2000). Remaining missing values and missing values in other variables were handled in the analyses by run-time deletion. We checked for any effects that are caused by potential outliers by using scatter plots (not shown).

\section{Variables}

Native Belgian-immigrant dichotomy. Because all the analyses are performed separately for native Belgian and immigrant pupils, it is important to explain how we distinguished between these two groups. Following the official definition of nonnative groups in Belgium and the Netherlands, the principal criterion was the birthplace of the pupils' grandmothers (see Phalet \& Swyngedouw, 2003). If these data were missing, we considered pupils' parents' birthplaces, as most nonnative pupils in Flanders are second- or thirdgeneration immigrants (Agirdag, 2010). We consider 11 broad ethnic groups: (1) Native Belgians (46.7\%, $n=1,329)$; (2) Western Europeans, including pupils of Dutch, French, or German origin $(5.6 \%, n=158)$; (3) Southern Europeans, including pupils of Italian or Spanish origin $(6.6 \%, n=188)$; (4) Turks (13.0\%, $n=369)$; (5) Moroccans (15.6\%, $n=444)$; (6) Other North Africans $(1.0 \%, n=29)$; (7) Eastern Europeans (5.8\%, $n=164)$; (8) Sub-Saharan 
Africans (1.8\%, $n=52)$; (9) Middle Easterners (1.2\%, $n=33)$; (10) Southeast Asians $(1.7 \%, n=48)$; (11) Others $(1.1 \%, n=31)$. As is common practice, and in line with the official Flemish definition of nonnative groups, students of Western European origins (Groups 1 and 2) were considered to be of native Belgian descent. Therefore, we created a dichotomous variable $(0=$ native, $1=$ immigrant).

Pupil-level variables. The dependent variable, global self-esteem, is measured by Rosenberg Self-Concept Scale (Rosenberg \& Simmons, 1972). The global self-esteem scale is the most widely used definition and measurement of self-esteem. This holds also true for studies in Belgium (see for instance Van Houtte et al., 2012). The scale consists of 12 items with 5 possible answers ranging between $1=$ absolutely disagree and $5=$ totally agree. Examples of items are, "I accept myself as I am," and "In general, I am content with myself." In our analysis we use the means scores. The scale yielded a Cronbach's alpha of .80. Mean score for native pupils is $3.824(S D=0.631$, Cronbach's alpha $=.82)$ and for immigrant pupils $3.756(S D=0.615$; see Table 1; Cronbach's alpha = .79). A "Q-Q" plot revealed that global selfesteem was highly normally distributed.

There is no single teacher support scale that is generally used. We measured teacher support by a scale consisting of 10 items (see Appendix 1), inspired by Brutsaert (2001) and Goodenow (1993), with five possible answers ranging from absolutely disagree (1) to totally agree (5). A multilevel confirmatory factor analysis (CFA; Muthén, 1994) revealed satisfactory fit for a one-factor model (root mean square error of approximation $[$ RMSEA $]=0.028$, standardized root mean square residual $[\mathrm{SRMR}]=0.032$, Cronbach's alpha $=.847)$. In our analysis we use the mean score, which ranges from 1.10 to 5.0. Mean score for native pupils is $4.096(S D=0.632)$ and mean score for immigrant pupils is $3.944(S D=0.664$; see Table 1). A $t$ test revealed that the mean difference for natives and immigrants is significant (mean difference $=0.152, t=6.240, p<.001$ ), indicating that immigrant students experience less support from their teachers than native students.

At the pupil level we controlled for grade $(0=$ fifth, $1=$ sixth $)$, gender ( $0=$ boy, $1=$ girl), SES, academic achievement and for immigrant pupils also for ethnicity. The SES of the pupils is measured by means of the occupational prestige of the father and mother (Erikson, Goldthorpe, \& Portocarero, 1979); the higher of the two is used as an indicator of the SES of the family. Native respondents have a mean SES of $5.437(S D=1.996)$ and immigrant pupils' mean SES score is $2.903(S D=2.018$; see Table 1$)$.

Academic achievement is measured by a test developed by Dudal and Deloof (2004), which is based on Flemish educational attainment levels 
Table I. Descriptive Statistics for Variables: Frequencies, Means (Continuous) and Proportions (Categorical) and standard deviations (SD)

\begin{tabular}{|c|c|c|c|c|c|c|}
\hline & \multicolumn{3}{|c|}{ Native Belgian } & \multicolumn{3}{|c|}{ Immigrants } \\
\hline & $N$ & Mean or \% & $S D$ & $N$ & Mean or $\%$ & $S D$ \\
\hline \multicolumn{7}{|l|}{ Pupil level } \\
\hline Global self-esteem & $\mathrm{I}, 477$ & 3.824 & 0.631 & 1,326 & 3.756 & 0.615 \\
\hline Teacher support & $\mathrm{I}, 486$ & 4.096 & 0.632 & $\mathrm{I}, 347$ & 3.944 & 0.664 \\
\hline Grade (I = sixth $)$ & $\mathrm{I}, 487$ & $26.83 \%$ & - & $\mathrm{I}, 358$ & $33.43 \%$ & - \\
\hline Gender $(I=$ girl $)$ & 1,479 & $52.13 \%$ & - & $\mathrm{I}, 348$ & $50.89 \%$ & - \\
\hline $\begin{array}{l}\text { SES (socioeconomic } \\
\text { status) }\end{array}$ & $\mathrm{I}, 480$ & 5.437 & 1.996 & $\mathrm{I}, 343$ & 2.903 & 2.018 \\
\hline $\begin{array}{l}\text { Academic achievement } \\
\text { (item response } \\
\text { theory [IRT]) }\end{array}$ & $\mathrm{I}, 446$ & 0.221 & 0.914 & 1,329 & -0.233 & 0.882 \\
\hline \multicolumn{7}{|l|}{ Ethnicity } \\
\hline Turkish & - & - & - & $\mathrm{I}, 358$ & $27.17 \%$ & \\
\hline Moroccan & - & - & - & $\mathrm{I}, 358$ & $32.70 \%$ & \\
\hline Other & - & - & - & $\mathrm{I}, 358$ & $40.13 \%$ & \\
\hline \multicolumn{7}{|l|}{ School Level } \\
\hline $\begin{array}{l}\text { Ethnic concentration } \\
\text { (\% immigrants) }\end{array}$ & 62 & $46.81 \%$ & 32.07 & 68 & 51.50 & 34.16 \\
\hline $\begin{array}{l}\text { Ethnic heterogeneity } \\
\text { (Herfindahl Index } \\
{[\mathrm{HI}] \text { ) }}\end{array}$ & 62 & -0.440 & 0.184 & 68 & $-0.46 \mathrm{I}$ & 0.198 \\
\hline $\begin{array}{l}\text { Teacher support } \\
\text { culture }\end{array}$ & 62 & 4.037 & 0.165 & 68 & 4.021 & 0.171 \\
\hline Size & 62 & 226.274 & 107.682 & 68 & 222.912 & 104.028 \\
\hline Sector (I = Catholic ) & 62 & $47.06 \%$ & & 68 & $48.39 \%$ & \\
\hline
\end{tabular}

outlined for students in the fifth grade of their primary education. The test consists of 60 items and covers elementary arithmetic, problem solving, fractions, point numbers, and long division. For each pupil, we calculated item response theory (IRT) scores, ranging from -2.967 to $2.396(M=0.001$, $S D=0.999)$. The mean score for native pupils is $0.221(S D=0.914)$ and for immigrant pupils it is $-0.233(S D=0.882$; see Table 1$)$. The Person Separation Index, that is, the equivalent for the alpha reliability score in IRT models, is 0.95 for this test.

Finally, for immigrant pupils we controlled for ethnicity. Because the group sizes of the above-listed ethnic groups are rather low, we distinguished 
three groups: We created two dummy variables for the two numerically largest immigrant groups in Belgium: (1) Turks (27\%) and (2) Moroccans (33\%), and other immigrant pupils are categorized as (3) "others" (40\%; see Table 1).

School-level variables. Two measures of ethnic school composition are included. First, we calculated the ethnic minority concentration by means of the proportion of (non-Western) immigrant respondents in a school in our database (see above). On average, the proportion of immigrant pupils is $51.50 \%(S D=34.16)$ and ranges from $2.631 \%$ to $100 \%$. In six schools, there were no native Belgian pupils, which reduced the number of schools for native pupils from 68 to 62 (see Table 1). The second indicator of ethnic school composition measures the ethnic diversity or heterogeneity within a school, expressed as the total number of different groups of nonnatives, corrected by their size. Following Lancee and Dronkers (2011), we used as an index of ethnic diversity the Herfindahl Index (HI) as used by Putnam (2007), though we multiplied this by -1 , as Putnam in fact calculated an index of homogeneity, whereas we are interested in heterogeneity. The index used as is calculated as $\left(\mathrm{p}_{\text {ethnic group } 1}\right)^{2}+\left(\mathrm{p}_{\text {ethnic group }}\right)^{2}+\ldots+\left(\mathrm{p}_{\text {ethnic group } \mathrm{n}}\right)^{2}$. We included the 11 ethnic groups listed above. The HI has a range of -1 to 0 ; a value of -1 implies no diversity at all; that is, there is only one ethnic group enrolled in the school. A value approaching zero means total diversity: Each pupil in the school has a different ethnic origin. In our data, the HI ranges between -0.875 and -0.177 . On average, schools have a HI score of -0.461 $(S D=0.198$; see Table 1$)$.

As outlined above, teacher support culture (school-level beliefs of teacher support) will be measured according to pupils' shared beliefs of teacher support. A customary aggregation strategy is the calculation of the means of individual-level responses of the students in schools (Stern, 1970). However, the aggregation has to be reliable and represent something truly shared at the group (school) level. To examine whether the beliefs of teacher support were truly shared, we calculated the mean rater reliability (MRR), based on the intraclass correlation of a one-way analysis of variance (ANOVA; see Glick, 1985), with the formula: MRR = (Between Mean Square - Within Mean Square) / Between Mean Square. It is only legitimate to speak of a teacher support culture when the MRR is higher than 0.60 (Shrout \& Fleiss, 1979). The teacher support culture scale yielded an MRR of 0.66 . This implies that the beliefs of teacher support are shared by pupils in the same school, and a teacher support culture actually exists. The mean score for teacher support culture for all schools is $4.021(S D=0.171$; see Table 1$)$, and it correlated significantly with the ethnic composition (Pearson $r=-.340, p<.01$ ). This 
Table 2. Variance Components for Global Self-Esteem From the Unconditional Models

\begin{tabular}{lll}
\hline Variance components & Natives & Immigrants \\
\hline Between school $\tau_{0}$ & $0.01 I^{* *}$ & $0.010^{*}$ \\
Within school $\sigma^{2}$ & $0.389^{* * *}$ & $0.369^{* * *}$ \\
$\%$ variance at school level & $2.77 \%^{* *}$ & $2.42 \% *$ \\
\hline
\end{tabular}

$* p<.05 . * p p .01 . * * p p<.001$.

indicates that there is a lower teacher support culture in schools with a higher share of immigrant pupils.

At the school level, we control for school size and school sector. We determined the school size from the total number of pupils, using data gathered from the Flemish Educational Department. The number of pupils varied from 91 in the smallest school to 526 in the largest. The schools have an average of 223 pupils $(S D=104.028)$. The variable school sector was split between nondenominational public schools (Score 0) and Catholic schools (Score 1). Reflecting the urban educational situation in Flanders, almost half of the schools in our data are Catholic schools (see Table 1 for descriptive statistics).

\section{Results}

In order to assess whether school context matters with respect to global selfesteem, the variance components from the unconditional models are shown in Table 2. We are particularly interested in the variance at the school level, which is computed as the between-school variance component divided by the sum of the within-school variance and between-school variance $\left(\tau_{0} /\left(\sigma^{2}+\right.\right.$ $\left.\tau_{0}\right)$ ). Table 2 demonstrates that, for native-Belgian pupils, $2.77 \%(p<.01)$ of the variance lies between schools, whereas for immigrant pupils the figure falls to $2.42 \%(p<.05)$. In other words, most of the variation occurs within schools, between pupils. Nevertheless, a small but significant amount of variance in global self-esteem is situated at a school level, which justifies the need for a multilevel analysis. However, given that only a small proportion of variance in global self-esteem is attributable to the school-level, we will be very cautious when we are interpreting the possible significant effects of school-level variables, in particular, when we are discussing the practical implication of our results (see Discussions section). 
Table 3. Results of Multilevel Analysis for Global Self-Esteem for Native Pupils. Gamma Coefficients $(\gamma)$, Standard Errors (in Parentheses), Standardized Gamma Coefficients $\left(\gamma^{*}\right)$, and Variance Components

\begin{tabular}{|c|c|c|c|c|}
\hline & & Model I & Model 2 & Model 3 \\
\hline \multicolumn{5}{|l|}{ School level } \\
\hline \multirow{2}{*}{$\begin{array}{l}\text { Ethnic concentration (\% } \\
\text { immigrants) }\end{array}$} & $\gamma$ & $0.004(0.002)$ & $0.006(0.002)$ & $0.005(0.001)$ \\
\hline & $\gamma^{*}$ & $0.197^{*}$ & $0.336 * * *$ & $0.283 * * *$ \\
\hline \multirow{2}{*}{$\begin{array}{l}\text { Ethnic heterogeneity } \\
\text { (Herfindahl Index) }\end{array}$} & $\gamma$ & $-0.293(0.214)$ & $-0.423(0.21 \mathrm{I})$ & $-0.362(0.179)$ \\
\hline & $\gamma^{*}$ & -0.092 & $-0.133 *$ & $-0.114^{*}$ \\
\hline \multirow[t]{2}{*}{ Size } & $\gamma$ & - & $0.000(0.000)$ & $0.001(0.000)$ \\
\hline & $\gamma^{*}$ & & 0.041 & $0.059 *$ \\
\hline \multirow[t]{2}{*}{ Sector (I = Catholic ) } & $\gamma$ & - & $-0.049(0.04 I)$ & $-0.004(0.035)$ \\
\hline & $\gamma^{*}$ & & -0.039 & -0.004 \\
\hline \multirow[t]{2}{*}{ Teacher support culture } & $\gamma$ & - & - & $-0.040(0.116)$ \\
\hline & $\gamma^{*}$ & & & -0.011 \\
\hline \multicolumn{5}{|l|}{ Pupil level } \\
\hline \multirow[t]{2}{*}{ Grade (I= sixth) } & $\gamma$ & - & $-0.00 \mathrm{I}(0.05 \mathrm{I})$ & $0.007(0.039)$ \\
\hline & $\gamma^{*}$ & & -0.001 & 0.005 \\
\hline \multirow[t]{2}{*}{ Gender (I= girl) } & $\gamma$ & - & $-0.109(0.035)$ & $-0.146(0.032)$ \\
\hline & $\gamma^{*}$ & & $-0.086 * * *$ & $-0.116 * * *$ \\
\hline \multirow[t]{2}{*}{ SES (socioeconomic status) } & $\gamma$ & - & $0.019(0.009)$ & $0.020(0.008)$ \\
\hline & $\gamma^{*}$ & & $0.062^{*}$ & $0.063^{* *}$ \\
\hline \multirow[t]{2}{*}{ Academic achievement } & $\gamma$ & - & $0.143(0.026)$ & $0.099(0.021)$ \\
\hline & $\gamma^{*}$ & & $0.207^{* * * *}$ & $0.144 * * *$ \\
\hline \multirow[t]{2}{*}{ Teacher support } & $\gamma$ & - & - & $0.40 I(0.038)$ \\
\hline & $\gamma^{*}$ & & & $0.40 \mathrm{I} * * *$ \\
\hline \multicolumn{5}{|l|}{ Variance components } \\
\hline Between schools & $\tau$ & $0.010 *$ & 0.002 & 0.001 \\
\hline Within school & $\sigma^{2}$ & $0.389 * * *$ & $0.350 * * *$ & $0.293 * * *$ \\
\hline
\end{tabular}

$*_{p}<.05 .{ }^{* * p} p .01 . * * * p<.001$.

Table 3 presents the results of multilevel regression analyses for native Belgian pupils. In Model 1 we enter the ethnic composition variables. It is clear that only the ethnic concentration is significantly related to native pupils' global self-esteem: In schools with a higher share of immigrant pupils, native pupils have a higher self-esteem (standardized coefficient $\gamma^{*}=.197$, $p<.05$ ). In Model 2 (Table 3), that is, as we include a set of control variables, 
the effect size of ethnic concentration substantially increases $\left(\gamma^{*}=.336\right.$, $p<.001)$. In this second model, the ethnic school heterogeneity has a significant effect on self-esteem as well: The larger the ethnic heterogeneity of the school, the lower native pupils' global self-esteem $\left(\gamma^{*}=-.133, p<.05\right)$. Although the included control variables are not the primary focus of this study, it is worth mentioning that girls have a lower global self-esteem than boys $\left(\gamma^{*}=-.086, p<.001\right)$, and pupils with a higher SES $\left(\gamma^{*}=.06, p<.05\right)$ and a higher academic achievement $\left(\gamma^{*}=.207, p<.001\right)$ exhibit higher levels of global self-esteem. In Model 3 (Table 3), we enter pupils' teacher support and schools' teacher support culture. The results indicate that teacher support is strongly related to the global self-esteem of native pupils $\left(\gamma^{*}=.401, p<.001\right)$, whereas teacher support culture at school level (pupils' shared beliefs of teacher support in schools) does not have a significant effect $\left(\gamma^{*}=.011, p=.73\right)$. In other words, feelings of teacher support of individual native pupils have a positive effect on their self-esteem, whereas the shared feelings of teacher support of the peer group does not have an impact. Most important, compared with Model 2, no substantial changes occur with respect to the effect of the ethnic school composition variables. This implies that, for native pupils, there is no mediation effect from teacher-pupil relationships.

Table 4 presents the results for immigrant pupils. Model 1 indicates that both ethnic concentration $\left(\gamma^{*}=.010, p=.80\right)$ and ethnic heterogeneity $\left(\gamma^{*}=.016\right.$, $p=.68)$ are unrelated to global self-esteem. When control variables are included in the second model (Table 4), this picture hardly changes. When we compare the above described Model 2 for native pupils (Table 3) with this Model 2 for immigrant pupils (Table 4), it is clear that the ethnic composition of schools have an influence on native Belgian pupils but not on immigrant pupils. The $t$-test comparisons of the unstandardized coefficients for both groups in Model 2 confirm that the impact of both ethnic minority concentration $(t=2.236, p<.05)$ and ethnic heterogeneity $(t=2.451, p<.05)$ differ for both groups. Moreover, the effects of the individual-level control variables are also different for immigrant pupils: Gender and SES do not have a significant effect for immigrant pupils, while they do for native pupils.

A clarification of these differences is provided in Model 3 (Table 4), that is, after we enter teacher-pupil relationship variables. Indeed, in this third model, the regression coefficients for ethnic concentration, gender, and SES are similar to those we found for native pupils: The ethnic concentration is positively related to self-esteem $\left(\gamma^{*}=.094, p<.05\right)$, girls exhibit lower levels of self-esteem $\left(\gamma^{*}=-.090, p<.001\right)$, and SES is positively associated with self-esteem $\left(\gamma^{*}=.065, p<.05\right)$. It is clear that the included teacher-pupil relationships exert a suppression effect for immigrant pupils. Moreover, for 
Table 4. Results of Multilevel Analysis for Global Self-Esteem for Immigrant Pupils. Gamma Coefficients $\gamma$, Standard Errors (in Parentheses), Standardized Gamma Coefficients $\gamma^{*}$, and Variance Components

\begin{tabular}{|c|c|c|c|c|}
\hline & & Model I & Model 2 & Model 3 \\
\hline \multicolumn{5}{|l|}{ School level } \\
\hline \multirow{2}{*}{$\begin{array}{l}\text { Ethnic concentration } \\
\text { (\% immigrants) }\end{array}$} & $\Gamma$ & $0.000(0.001)$ & $0.001(0.001)$ & $0.002(0.001)$ \\
\hline & $\gamma^{*}$ & 0.010 & 0.045 & $0.094 *$ \\
\hline \multirow{2}{*}{$\begin{array}{l}\text { Ethnic heterogeneity } \\
\text { (Herfindahl Index) }\end{array}$} & $\Gamma$ & $0.048(0.118)$ & $0.158(0.108)$ & $0.017(0.099)$ \\
\hline & $\gamma^{*}$ & 0.016 & 0.051 & 0.006 \\
\hline \multirow[t]{2}{*}{ Size } & $\Gamma$ & - & $0.001(0.001)$ & $0.001(0.001)$ \\
\hline & $\gamma^{*}$ & & 0.023 & 0.055 \\
\hline \multirow[t]{2}{*}{ Sector (I = Catholic) } & $\Gamma$ & - & $0.008(0.038)$ & $0.012(0.035)$ \\
\hline & $\gamma^{*}$ & & 0.006 & 0.010 \\
\hline \multirow[t]{2}{*}{ Teacher support culture } & $\Gamma$ & - & - & $0.225(0.116)$ \\
\hline & $\gamma^{*}$ & & & $0.062^{*}$ \\
\hline \multicolumn{5}{|l|}{ Pupil level } \\
\hline \multirow[t]{2}{*}{ Grade (I= sixth) } & $\Gamma$ & - & $0.074(0.039)$ & $0.059(0.036)$ \\
\hline & $\gamma^{*}$ & & $0.057^{*}$ & 0.045 \\
\hline \multirow[t]{2}{*}{ Gender ( $I=$ girl $)$} & $\Gamma$ & - & $-0.048(0.035)$ & $-0.1 I I(0.033)$ \\
\hline & $\gamma^{*}$ & & -0.039 & $-0.090 * * *$ \\
\hline \multirow[t]{2}{*}{ SES (socioeconomic status) } & $\Gamma$ & - & $0.015(0.010)$ & $0.020(0.009)$ \\
\hline & $\gamma^{*}$ & & 0.048 & $0.065^{*}$ \\
\hline \multirow[t]{2}{*}{ Academic achievement } & $\Gamma$ & - & $0.136(0.022)$ & $0.078(0.022)$ \\
\hline & $\gamma^{*}$ & & $0.195 * * *$ & $0.112^{* * *}$ \\
\hline \multicolumn{5}{|c|}{ Ethnicity (reference category: Other) } \\
\hline \multirow[t]{2}{*}{ Turkish } & $\Gamma$ & - & $0.054(0.047)$ & $0.074(0.042)$ \\
\hline & $\gamma^{*}$ & & 0.039 & 0.053 \\
\hline \multirow[t]{2}{*}{ Moroccan } & $\Gamma$ & - & $-0.096(0.04 I)$ & $-0.089(0.037)$ \\
\hline & $\gamma^{*}$ & & $-0.073 *$ & $-0.068^{*}$ \\
\hline \multirow[t]{2}{*}{ Teacher support } & $\Gamma$ & - & - & $0.378(0.028)$ \\
\hline & $\gamma^{*}$ & & & $0.407^{* * *}$ \\
\hline \multicolumn{5}{|l|}{ Variance components } \\
\hline Between schools & $\tau_{0}$ & $0.009 *$ & $0.008^{*}$ & 0.001 \\
\hline Within school & $\sigma^{2}$ & $0.369 * * *$ & $0.349 * * *$ & $0.287^{* * *}$ \\
\hline
\end{tabular}

$* p<.05 . * * p<.01 . * * * p<.001$.

immigrant pupils not only does teacher support of individual pupils have a positive effect $\left(\gamma^{*}=.407, p<.001\right)$, but there is also a small but significant positive effect of schools' teacher support culture on pupils' global selfesteem $\left(\gamma^{*}=.062, p<.05\right)$. This evidence suggests that teacher-pupil 
Table 5. A Summary of Found Relationships Between Ethnic Composition, Teacher Support, and Self-Esteem for Native Belgian and Immigrant Students

\begin{tabular}{lll}
\hline & \% Immigrants at school & Teacher support \\
\hline Native Belgian students & Self-esteem $^{\mathrm{b}}$ & Self-esteem $^{\mathrm{c}}$ \\
Immigrants students $^{\mathrm{Im}}$ & Self-esteem $^{\mathrm{a}}$ & Self-esteem $^{\mathrm{c}}$ \\
\hline
\end{tabular}

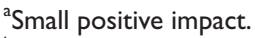

bMedium positive impact.

'Large positive impact.

relationships - measured at both pupil and school level — indeed mediate the impact of ethnic school composition on immigrant pupils' self-esteem: Supportive teacher-pupil relationships buffer the potential negative effect of schools with a low ethnic concentration on immigrant pupils' self-esteem. In Table 5 we summarize our results for both immigrant and native Belgian students.

\section{Discussion}

\section{Conclusions}

Opponents of ethnic school desegregation policies frequently refer to the empirical evidence that has indicated that ethnic minority pupils exhibit lower levels of self-esteem in de facto desegregated schools. They argue that school desegregation might not be as beneficial for ethnic minorities as is generally believed because it might harm pupils' self-concepts (see Bankston \& Zhou, 2002). Although there are indeed empirical studies that have demonstrated the favorable effect of ethnic minority concentration on the selfesteem of ethnic minority pupils, these studies are mainly conducted in the United States (see meta-review by Gray-Little \& Hafdahl, 2000). The contributions of this study are twofold: We not only assess the impact of ethnic minority concentration and ethnic heterogeneity on the global self-esteem of both native and immigrant pupils, but we also examine the highly neglected role of teacher-pupil relationships as a mediating mechanism between ethnic school composition and global self-esteem.

Overall, the results of our multilevel analyses are noticeably different for natives and immigrant pupils. We find that native pupils exhibit higher global self-esteem in schools with a greater share of immigrant pupils and in those with less ethnic heterogeneity. However, for immigrant pupils, none of the measures of ethnic school composition was initially related to their global 
self-esteem, even after taking into account a set of control variables. Although this finding contrasts with previous studies from the United States that particularly suggested that ethnic minority (mostly Black) pupils' self-esteem is affected by ethnic school composition (see Gray-Little \& Hafdahl, 2000), our results are in line with the only study we are aware of that is conducted in a similar European context. That is, Verkuyten and Thijs also found that the share of ethnic minority pupils at school was positively related to the selfesteem of ethnic majority (native Dutch) pupils, although it did not have an effect on the self-esteem of ethnic minority pupils.

The positive effect of ethnic minority concentration on native Belgian pupils' self-esteem can be framed by the reference group theory and be explained by the social comparison processes (see Van Houtte et al., 2012). That is, in schools with a larger ethnic minority concentration, native pupils are likely to experience relative gratification as they compare themselves with their less esteemed ethnic minority peers. The contrast between both groups might explain why the self-esteem of native pupils increases in those schools. The reason why ethnic minority concentration was (initially) not related to immigrant pupils' self-esteem has to do with the mediating role of teacher-pupil relationships. Indeed pupils' feelings of teacher support and schools' teacher support culture were both positively associated with higher global self-esteem for immigrant pupils. Most important, we find that teacher-pupil relationships suppress the effect of ethnic school composition on the global self-esteem of immigrant pupils: After entering teacher support and teacher support culture, we found that ethnic minority concentration is also negatively related to immigrant pupils' self-esteem. Moreover, regarding the impact of gender and SES for immigrant pupils, we find evidence of the same buffering role of supportive teacher-pupil relationships. For native pupils, we did not find a mediation effect from teacher-pupil relationships. It seems that in Flanders there are divergent effects of ethnic minority concentration for natives and immigrant pupils due to teacher-pupil relationships. This is probably also the case in the Netherlands, but we cannot be sure of this statement as Verkuyten and Thijs (2004) did not examine the impact of teacher-pupil relationships.

It might be the case that our findings contradict studies conducted in the United States because the situation of ethnic minorities in Flanders might after all differ from the situation of ethnic minorities in the United States. That is ethnic minorities in Flanders are mostly poor, second-generation immigrants from Morocco and Turkey-as described in the Introduction section - whereas in the United States the ethnic minorities are from a wide range of socioeconomic, racial, and ethnic backgrounds (e.g., Blacks, 
Hispanics, Asians, etc.). This underlines the importance of testing wellestablished hypotheses in different national contexts and conducting more studies in European countries to clarify whether the findings of our study and those of Verkuyten and Thijs (2004) constitute a particular finding for the (West-) European educational context.

One potential limitation of this study is that we only considered the influence of school-level and pupil-level variables and failed to include any classroom-level variables. However, we did this because our sample was not suitable for running a three-level model, and the focus of the research project was on the impact of school composition.

\section{Implications for Policy and Practitioners}

This study has important implications for educational policy and practice. With respect to educational policy, our results suggest that the impact of ethnic school composition on self-esteem should not constitute a major argument against school desegregation. First, the school context does only account for a small variation in pupils' global self-esteem. Second, the potential negative impact of lower ethnic concentration on immigrant pupils is suppressed by perceived teacher-pupil relationships. Finally, the presence of immigrant pupils at a school might even enhance native pupils' global self-esteem. Nevertheless, the decision as to whether or not to desegregate schools should not be based solely on the criterion of self-esteem (see also Agirdag \& Van Houtte, 2011; Agirdag, Van Houtte, \& Van Avermaet, 2012).

Regarding educational practice, the results of this study point to the overwhelming importance of teacher-pupil relationships for pupils' global selfesteem, since teacher support has by far the greatest effect in our models. Pupils' experiences of supportive relationships with their teachers are very strongly associated with higher levels of self-esteem, and for immigrant pupils such supportive relationships can even compensate for the negative impact of ethnic school composition. However, most school-based interventions that aim to enhance self-concept of pupils focus solely on individual pupils and fail to address the social relationships between teachers and pupils (see Elbaum \& Vaughn, 2001; King, Vidourek, Davis, \& McClellan, 2002). Nevertheless, individual teachers are able to enhance self-esteem and buffer the potential negative effects of school composition on it. The question of how teachers can do so, however, is beyond the scope of this study. Regarding this issue, we refer to the influential work of Lawrence (2006), who provides an extensive range of activities and strategies for teachers to enhance pupils' self-esteem. 


\section{Appendix A}

The items from the teacher support scale.

1. My teachers dare to make a fool of me in the presence of others. (reversed)

2. If I want to tell something, my teachers pretend not to hear me. (reversed)

3. My teachers accept me as I am.

4. My teachers trust me.

5. I have the feeling that my teachers care little about me. (reversed)

6. My teachers only pay attention to my mistakes. (reversed)

7. I think that my teachers do not believe that I can do something right. (reversed)

8. Most teachers at this school are interested in me.

9. Teachers here are not interested in people like me. (reversed)

10. The teachers here respect me.

\section{Acknowledgments}

This study was performed while being a recipient of both a fellowship of the Belgian American Educational Foundation and a fellowship of the Fulbright Commission Belgium. Thanks are due to Professor Emile Boulpaep and Ms. Margaret Nicholson for their support.

\section{Declaration of Conflicting Interests}

The author(s) declared no potential conflicts of interest with respect to the research, authorship, and/or publication of this article.

\section{Funding}

The author(s) disclosed receipt of the following financial support for the research, authorship, and/or publication of this article: This article was made possible through funding from the Research Foundation Flanders (FWO-project G.040908).

\section{References}

Agirdag, O. (2010). Exploring bilingualism in a monolingual school system: Insights from Turkish and native students from Belgian schools. British Journal of Sociology of Education, 31(3), 307-321.

Agirdag, O., Demanet, J., Van Houtte, M., \& Van Avermaet, P. (2011). Ethnic school composition and peer victimization: A focus on the interethnic school climate. International Journal of Intercultural Relations, 35(4), 465-473. 
Agirdag, O., \& Van Houtte, M. (2011). A tale of two cities: Bridging families and schools. Educational Leadership, 68(8), 42-46.

Agirdag, O., Van Houtte, M., \& Van Avermaet, P. (2011). Ethnic school context and the national and sub-national identifications of pupils. Ethnic and Racial Studies, 34(2), 357-378.

Agirdag, O., Van Houtte, M., \& Van Avermaet, P. (2012). Why does the ethnic and socio-economic composition of schools influence math achievement? The role of sense of futility and futility culture. European Sociological Review, 28(3), 366-378.

Bankston, C. L. I., \& Zhou, M. (2002). Being well vs. doing well: Self-esteem and school performance among immigrant and nonimmigrant racial and ethnic groups. International Migration Review, 36(2), 389-415.

Birch, S. H., \& Ladd, G. W. (1997). The teacher-child relationship and children's early school adjustment. Journal of School Psychology, 35(1), 61-79.

Bowlby, J. (1982). Attachment and loss: Retrospect and prospect. American Journal of Orthopsychiatry, 52(4), 664-678.

Brutsaert, H. (1990). Changing sources of self-esteem among girls and boys in secondaryschools. Urban Education, 24(4), 432-439.

Brutsaert, H. (2001). Co-educatie: Studiekansen en kwaliteit van het schoolleven [Coeducation: Educational opportunities and the quality of school life]. LeuvenApeldoorn, Belgium: Garant.

Buyse, E., Verschueren, K., Verachtert, P., \& Van Damme, J. (2009). Predicting school adjustment in early elementary school: Impact of teacher-child relationship quality and relational classroom climate. Elementary School Journal, 110(2), 119-141.

Chan, W. Y., \& Birman, D. (2009). Cross-and same-race friendships of Vietnamese immigrant adolescents: A focus on acculturation and school diversity. International Journal of Intercultural Relations, 33(4), 313-324.

Coleman, J. S. (1988). Social capital in the creation of human-capital. American Journal of Sociology, 94, 95-120.

Cooper, C. E., \& Crosnoe, R. (2007). The engagement in schooling of economically disadvantaged parents and children. Youth \& Society, 38(3), 372-391.

Crosnoe, R., Johnson, M. K., \& Elder, G. H. (2004). Intergenerational bonding in school: The behavioral and contextual correlates of student-teacher relationships. Sociology of Education, 77(1), 60-81.

Davis, J. A. (1966). Campus as a frog pond: Application of theory of relative deprivation to career decisions of college men. American Journal of Sociology, 72(1), 17-31.

Drury, D. W. (1980). Black self-esteem and desegregated schools. Sociology of Education, 53(2), 88-103. 
Dudal, P., \& Deloof, G. (2004). Vrij centrum voor leerlingenbegeleiding. Leerlingenvolgsysteem. Wiskunde: Toetsen 5-Basisboek [Center for student counseling. Pupil-monitoring-system. Mathematics: Keys 5-Basic book]. Antwerpen, Belgium: Garant.

Elbaum, B., \& Vaughn, S. (2001). School-based interventions to enhance the selfconcept of students with learning disabilities: A meta-analysis. Elementary School Journal, 101(3), 303-329.

Erikson, R., Goldthorpe, J. H., \& Portocarero, L. (1979). Intergenerational class mobility in 3 Western European societies: England, France, and Sweden. British Journal of Sociology, 30(4), 415-441.

Festinger, L. (1954). A theory of social comparison processes. Human Relations, $7(2), 117-140$.

Glick, W. H. (1985). Conceptualizing and measuring organizational and psychological climate: Pitfalls in multilevel research. Academy of Management Review, 10(3), 601-616.

Goodenow, C. (1993). The psychological sense of school membership among adolescents: Scale development and educational correlates. Psychology in the Schools, 30(1), 79-90.

Gray-Little, B., \& Carels, R. A. (1997). The effect of racial dissonance on academic self-esteem and achievement in elementary, junior high school students. Journal of Research on Adolescence, 7(2), 109-131.

Gray-Little, B., \& Hafdahl, A. R. (2000). Factors influencing racial comparisons of self-esteem: A quantitative review. Psychological Bulletin, 126(1), 26-54.

Hamre, B. K., \& Pianta, R. C. (2001). Early teacher-child relationships and the trajectory of children's school outcomes through eighth grade. Child Development, 72(2), 625-638.

Harter, S. (1996). Teacher and classmate influences on scholastic motivation, selfesteem, and level of voice in adolescents. In J. Juvonen \& K. Wentzel (Eds.), Social motivation: Understanding children's school adjustment (pp. 11-42). New York. NY: Cambridge University Press.

Hoffman, A. J., Knight, L. F. M., \& Wallach, J. (2007). Gardening activities, education, and self-esteem: Learning outside the classroom. Urban Education, 42(5), 403-411.

Huisman, M. (2000). Imputation of missing item responses: Some simple techniques. Quality and Quantity, 34(4), 331-351.

Jaccard, J., Turrisi, R., \& Wan, C. K. (1990). Interaction effects in multiple regression. Newbury Park, CA: SAGE.

Juvonen, J., Nishina, A., \& Graham, S. (2001). Self-views versus peer perceptions of victim status among early adolescents. In J. Juvonen \& S. Graham (Eds.), Peer harassment in school: The plight of the vulnerable and victimized (pp. 105-124). New York, NY: Guilford. 
King, K. A., Vidourek, R. A., Davis, B., \& McClellan, W. (2002). Increasing selfesteem and school connectedness through a multidimensional mentoring program. Journal of School Health, 72(7), 294-299.

Lancee, B., \& Dronkers, J. (2011). Ethnic, religious and economic diversity in Dutch neighbourhoods: Explaining quality of contact with neighbours, trust in the neighbourhood and inter-ethnic trust. Journal of Ethnic and Migration Studies, 37(4), 597-618.

Lawrence, D. (2006). Enhancing self-esteem in the classroom (3rd ed.). London: SAGE.

Marsh, H. W. (1987). The big-fish little-pond effect on academic self-concept. Journal of Educational Psychology, 79(3), 280-295.

Marsh, H. W. (1990). Causal ordering of academic self-concept and academic achievement: A multiwave, longitudinal panel analysis. Journal of Educational Psychology, 82(4), 646-656.

Merton, R. K. (1968). Continuities in the theory of reference groups and social structure. In R. K. Merton (Ed.), Social theory and social structure (pp. 335-440). New York, NY: Free Press.

Mirowsky, J., \& Ross, C. E. (1989). Social causes of psychological distress. New York, NY: de Gruyter.

Muller, C. (2001). The role of caring in the teacher-student relationship for at-risk students. Sociological Inquiry, 71(2), 241-255.

Murray, C., \& Greenberg, T. M. (2000). Children's relationship with teachers and bonds with school an investigation of patterns and correlates in middle childhood. Journal of School Psychology, 38(5), 423-445.

Muthén, B. (1994). Multilevel covariance structure analysis. In J. Hox \& I. Kreft (Eds.), Multilevel modeling: A special issue of Sociological Methods \& Research, 22, 376-398.

Ogbu, J. (1991). Immigrant and involuntary minorities in comparative perspective. In M. Gibson \& J. Ogbu (Eds.), Minority status and schooling: A comparative study of immigrant and involuntary minorities (pp. 3-33). New York, NY: Garland.

Phalet, K., \& Swyngedouw, M. (2003). Measuring immigrant integration: The case of Belgium. Migration Studies, 40(152), 773-803.

Powell, G. J. (1985). Self-concepts among Afro-American students in racially isolated minority schools: Some regional differences. Journal of the American Academy of Child and Adolescent Psychiatry, 24(2), 142-149.

Pullmann, H., \& Allik, J. (2008). Relations of academic and general self-esteem to school achievement. Personality and Individual Differences, 45(6), 559-564.

Putnam, R. D. (2007). E pluribus unum: Diversity and community in the twenty-first century. The 2006 Johan Skytte Prize Lecture. Scandinavian Political Studies, $30(2), 137-174$. 
Reddy, R., Rhodes, J. E., \& Mulhall, P. (2003). The influence of teacher support on student adjustment in the middle school years: A latent growth curve study. Development and Psychopathology, 15(01), 119-138.

Roeser, R. W., \& Eccles, J. S. (1998). Adolescents' perceptions of middle school: Relation to longitudinal changes in academic and psychological adjustment. Journal of Research on Adolescence, 8(1), 123-158.

Rosenberg, M., Schooler, C., Schoenbach, C., \& Rosenberg, F. (1995). Global selfesteem and specific self-esteem: Different concepts, different outcomes. American Sociological Review, 60(1), 141-156.

Rosenberg, M., \& Simmons, R. G. (1972). Black and white self-esteem: The urban school child. Washington, DC: American Sociological Association.

Ryan, M., \& Patrick, H. (2001). The classroom social environment and changes in adolescents' motivation and engagement during middle school. American Educational Research Journal, 38(2), 437-460.

Ryan, M., Stiller, J. D., \& Lynch, J. H. (1994). Representations of relationships to teachers, parents, and friends as predictors of academic motivation and selfesteem. The Journal of Early Adolescence, 14(2), 226-249.

St. John, N. (1975). School desegregation: Outcome for children. Hoboken, NJ: Wiley.

Shrout, P. E., \& Fleiss, J. L. (1979). Intraclass correlations: Uses in assessing rater reliability. Psychological Bulletin, 86(2), 420-428.

Singer, J. D. (1998). Using SAS PROC MIXED to fit multilevel models, hierarchical models, and individual growth models. Journal of Educational and Behavioral Statistics, 23(4), 323-355.

Stephan, W. G. (1978). School-desegregation: Evaluation of predictions made in Brown v Board of Education. Psychological Bulletin, 85(2), 217-238.

Stern, G. (1970). People in context: Measuring person-environment congruence in education and industry. Hoboken, NJ: Wiley.

Thrupp, M., Lauder, H., \& Robinson, T. (2002). School composition and peer effects. International Journal of Educational Research, 37(5), 483-504.

Van Houtte, M. (2005). Climate or culture? A plea for conceptual clarity in school effectiveness research. School Effectiveness and School Improvement, 16(1), 71-89.

Van Houtte, M., Demanet, J., \& Stevens, P. A. J. (2012) Self-esteem of academic and vocational students: Does within-school tracking sharpen the difference? Acta Sociologica, 55(1), 73-89.

Van Houtte, M., \& Stevens, P. A. J. (2009) School ethnic composition and students' integration outside and inside schools in Belgium. Sociology of Education, 82(3), 217-239. 
Van Maele, D., \& Van Houtte, M. (2011). The quality of school life: Teacherstudent trust relationships and the organizational school context. Social Indicators Research, 100(1), 85-100.

Verkuyten, M., \& Thijs, J. (2002). Racist victimization among children in The Netherlands: The effect of ethnic group and school. Ethnic and Racial Studies, 25(2), 310-331.

Verkuyten, M., \& Thijs, J. (2004). Global and ethnic self-esteem in school context: Minority and majority groups in the Netherlands. Social Indicators Research, 67(3), 253-281.

Wentzel, K. R. (1998). Social relationships and motivation in middle school: The role of parents, teachers, and peers. Journal of Educational Psychology, 90(2), 202-209.

Yogev, A., \& Ilan, Y. (1987). Does self-esteem affect educational aspirations: The case of the ethnic enclave. Urban Education, 22(2), 182-202.

Zirkel, S. (2005). Ongoing issues of racial and ethnic stigma in education 50 years after Brown v. Board. The Urban Review, 37(2), 107-126.

\section{Bios}

Orhan Agirdag, $\mathrm{PhD}$, is a sociologist of education, associated to research group CuDOS at the Ghent University. He is currently also a visiting scholar at the UCLA, Civil Rights Project. His research interests are school segregation, ethnic and racial inequalities in education and bilingualism.

Mieke Van Houtte, PhD, is associate professor at the Department of Sociology, Research Group CuDOS, at Ghent University. Her research interests cover diverse topics within the sociology of education, particularly the effects of school characteristics.

Piet Van Avermaet, $\mathrm{PhD}$, is the director of the Centre for Diversity and Learning at Ghent University where he teaches multicultural studies. His main research interests are diversity and social inequality in education, educational linguistics and integration of immigrants. 